\title{
Um país e seus fantasmas: a tradição autoritária no Brasil
}

\author{
A country and its ghosts: the authoritarian tradition in Brazil \\ Un pais y sus fantasmas: la tradición autoritaria en Brasil \\ Luiz Alberto de Souza ${ }^{1 *}$ \\ ${ }^{1}$ Universidade Federal de Santa Catarina, Florianópolis/ SC - Brasil
}

Schwarcz, Lilia Katri Moritz. Sobre o autoritarismo brasileiro. São Paulo: Companhia das Letras, 2019. 273 p.

Para nós, brasileiros, o alerta soou com força em 2013. Em junho daquele ano, após algumas semanas com as ruas das principais cidades do País tomadas por estudantes e trabalhadores que protestavam contra as tarifas do transporte público e reivindicavam o seu direito à cidade, um fenômeno estranho iniciou. Vozes cada vez mais hostis contra a política e os políticos em geral começaram a fazer coro em meio aos tradicionais gritos de guerra das esquerdas. Palavras de ordem, cartazes, faixas com os dizeres mais vagos e contraditórios eram levantadas por homens e mulheres que aparentemente saíam às ruas em protesto pela primeira vez em suas vidas. Em pouco tempo, militantes, ativistas e simpatizantes de qualquer partido, sindicato ou coletivo alinhado às diferentes causas progressistas começaram a ser hostilizados ou agredidos em meio às manifestaçóes. Durante os tumultos, a polícia deu início a uma seleçấo cada vez mais óbvia de quem deveria ou não ser reprimido. $\mathrm{O}$ vermelho dos trabalhistas, socialistas e comunistas, bem como o negro dos anarquistas diluía-se na multidão. O verde e o amarelo de um amontoado ideologicamente amorfo, mas que se anunciava como "nacionalista", passaram a predominar. Logo, ambos os grupos não podiam mais conviver nas ruas. As cores das camisetas, bandeiras e adesivos indicavam não mais adversários, mas inimigos. $\mathrm{A}$ violência fez sua escalada da palavra ao ato. Gente foi intimidada, constrangida, humilhada, espancada, perseguida, presa, mutilada por conta das suas ideias, opiniôes e açôes políticas. Nos meses seguintes, as bandeiras negras e vermelhas praticamente desapareceram das ruas e, no seu lugar, viam-se, em número sempre crescente, as do Brasil. $\mathrm{O}$ movimento de 2013 entrou para a história do País sob diferentes nomes ("Manifestaçôes dos 20 centavos", "Manifestaçôes de Ju-

DOI: http://dx.doi.org/10.1590/2237-101X02104515

Resenha recebida em 17 de fevereiro de 2019 e aceita para publicaçáo em 7 de abril de 2020.

* Doutor em História Cultural pela Universidade Federal de Santa Catarina, Florianópolis / SC - Brasil. E-mail: luiz_alberto82@yahoo.com.br. ORCID: https://orcid.org/0000-0003-2511-1228. 
nho", "Jornadas de Junho") e tornou-se uma espécie de enigma sociopolítico. O que havia acontecido? Quem eram aquelas pessoas? O que queriam? O tempo passou e vieram outros acontecimentos igualmente atordoantes: o início da Operação Lava Jato, a campanha eleitoral de 2014, o golpe que destituiu a presidenta Dilma Rousseff, o assassinato da vereadora Marielle Franco, a prisão em segunda instância do ex-presidente Luiz Inácio Lula da Silva e, finalmente, as eleiçóes de 2018 e a vitória de Jair Bolsonaro. Apesar das suas particularidades, todos esses eventos, no entanto, continuaram repercutindo as mesmas cenas ensaiadas naquele grande laboratório que foi 2013. Hoje, em meio a outras tragédias, ainda nos perguntamos: o que houve e o que está havendo com o País? A historiadora Lilia Moritz Schwarcz é uma das pessoas que fazem publicamente essas indagaçóes. Seu livro, Sobre o autoritarismo brasileiro, publicado no começo de 2019, apenas alguns meses após o pleito que levou a extrema-direita à Presidência da República, é um ensaio de reflexão objetiva sobre o nosso momento social, político e cultural, mas também testemunho eloquente da hora em que foi escrito.

Schwarcz, contudo, não está sozinha nesse esforço. Nos últimos anos as livrarias brasileiras vêm expondo uma quantidade cada vez maior de títulos que se propóem explicar a nossa abismante conjuntura. Intelectuais como Jessé Souza ( $A$ elite do atraso: da escravidão à Lava Jato, 2017), Esther Solano (O ódio como politica: a reinvenção das direitas no Brasil, 2018), Mário Magalhães (Sobre lutas e lágrimas: uma biografia de 2018, o ano em que o Brasil flertou com o apocalipse, 2019), Rosana Pinheiro-Machado e Adriano de Freixo (Brasil em transe: bolsonarismo, nova direita e desdemocratização, 2019) ou Marcia Tiburi (Delírio do poder: psicopoder e loucura coletiva na era da desinformação, 2019) sáo apenas alguns nomes de uma extensa lista de autores que, sob diferentes perspectivas, têm buscado compreender o fenômeno da ascensáo político-institucional do neofascismo no Brasil. Uma busca por entendimento, aliás, similar àquela realizada por outros intelectuais que, também neste instante, em diversos países, tentam decifrar o aparente colapso dos seus respectivos sistemas políticos. Caso, por exemplo, dos estadunidenses Steven Levitsky e Daniel Ziblatt (Como as democracias morrem, 2018), do alemão Yascha Mounk ( $O$ povo contra a democracia: por que nossa liberdade corre perigo e como salvá-la, 2018) e do francês Manuel Castells (Ruptura: a crise da democracia liberal, 2018). Muitos desses, certamente não por acaso, tornados verdadeiros best-sellers no mercado editorial brasileiro.

A despeito da sua formação interdisciplinar, é sobretudo sob o ângulo da História que Schwarcz compôe o seu livro. Área na qual transita com intimidade e desenvoltura. Graduada em História e com mestrado e doutorado em Antropologia Social pela Universidade de Sáo Paulo (USP), a pesquisadora é atualmente professora titular do Departamento de Antropologia da Faculdade de Filosofia, Letras e Ciências Humanas da mesma universidade e autora de diversas obras consideradas referências tanto no campo da Antropologia quanto da História. 
Títulos como $O$ espetáculo das raças: cientistas, instituiçôes e pensamento racial no Brasil: 1870-1930 (1993), As barbas do Imperador: D. Pedro II, um monarca nos Trópicos (1998) e Lima Barreto: triste visionário (2017) são apenas alguns dos livros que compóem a sua extensa produção intelectual.

Em nota à Introdução de Sobre o autoritarismo brasileiro, a autora nos informa que seu texto foi concebido a partir de material coletado para Brasil: uma biografia, livro que Schwarcz publicou em 2014 em coautoria com Heloisa Starling, além de colunas publicadas no jornal Nexo, nos últimos cinco anos. Essa origem comum, tanto na atividade de divulgação historiográfica quanto na análise e comentário políticos, ajuda a explicar certos traços gerais da obra. Há certo senso de urgência e uma ânsia por comunicabilidade impregnados em Sobre o autoritarismo brasileiro. Características que, no entanto, não atiram o livro nem no fosso do ativismo excessivamente parcial, nem no didatismo simplificador. $O$ ensaio de Schwarcz é sim comprometido com uma visão liberal, democrática e progressista da história, mas também lúcido o bastante para colocar, sempre que necessário, esse mesmo liberalismo em perspectiva. No mais, é uma obra amplamente acessível, sem, contudo, reduzir-se a esquematismos, nem diminuir o nível dos debates que propóe.

A autora divide o seu texto em oito capítulos, cada um correspondente ao que chama de "raízes do autoritarismo no Brasil". Um conjunto de práticas, ideias e valores socialmente compartilhados que definem a nossa secular tradição de discriminações, exclusóes e violências. No livro, temas como "escravidão e racismo", "mandonismo", "patrimonialismo”, “corrupção", “desigualdade social", "violência", "raça e gênero" e "intolerância" são tratados como fenômenos historicamente constituídos, mas com presenças e repercussóes muito vívidas no cotidiano brasileiro atual. Valendo-se tanto de bibliografia especializada sobre cada um dos temas quanto de fontes jornalísticas e dados oficiais, Schwarcz constrói breves, porém amplos panoramas acerca de cada um desses problemas.

No primeiro capítulo, Schwarcz trata o tema da escravidão e do racismo no Brasil. Para a autora, o escravismo tornou-se um sistema tão firmemente arraigado à nossa sociedade que se transformou numa espécie de linguagem. Fenômeno onipresente, inescapável, que abarcava todas as instituições e práticas sociais e que acabou por naturalizar a concentração do poder e riqueza nas mãos de uma minoria senhorial pretensamente branca. Seus fundamentos, contudo, não teriam sido eliminados com a Lei Áurea, de 1888, e a virtual emancipação dos escravizados. O pós-abolição foi marcado pela continuidade do trato desigual com relação aos diversos povos e etnias que constituem a população brasileira. E, mesmo com as conquistas sociais e políticas das últimas décadas, ainda se vive num país onde a realidade da discriminação, sobretudo das pessoas negras, é a regra praticada, inclusive, por agentes do Estado.

Em seguida, no segundo capítulo, Schwarcz aborda a questão do mandonismo. A historiadora, mais uma vez, vê no nosso 
passado colonial e escravista a gênese de um fenômeno que ainda hoje nos constitui como sociedade. Para ela, a colônia, ao combinar o uso de trabalhadores escravizados, grande propriedade monocultora, domínios privados exercidos pelos grandes senhores e a praticamente inexistente presença do Estado, teria contribuído para formar, ainda nos primeiros anos da ocupação, uma espécie de fidalguia local, enobrecida por "mérito" próprio e legitimada pela extrema concentração de riqueza e poder político. Nessa perspectiva, o mandonismo, o favor, o personalismo seriam elementos basilares da nossa experiência política, e, de certo modo, explicariam os novos e velhos coronéis que ainda hoje atuam no espaço público como se governassem suas estâncias.

No terceiro capítulo, a autora discute o patrimonialismo. Isto é, a prática de apropriação privada, por parte dos representantes do Estado, do bem público e da riqueza nacional. Partindo de uma frase do historiador José Murilo de Carvalho ("nossa República nunca foi republicana”), Schwarcz discorre sobre a dificuldade de sedimentarmos uma verdadeira cultura cívica no País, bem como sobre o desinteresse das nossas elites pela realização de um Estado que de fato garanta à população o pleno exercício dos seus direitos sociais básicos. Aqui, mais uma vez, destaca-se o enraizamento histórico do problema e suas conexóes com fenômenos e processos anteriormente tratados no livro.

O problema da corrupção é o quarto tema tratado pela pesquisadora. Segundo ela, o mau emprego do erário e o consequente desequilíbrio e desorganização das políti- cas públicas é uma realidade antiga, tratada sob diferentes nomes ao longo da nossa história (durante o Império, por exemplo, falava-se em "gatunagem”). Apesar de perceber a corrupção como elemento fundamental da vida política e social brasileira, Schwarcz, no entanto, critica a opinião que a vê como fenômeno particular ou endêmico do País. Contrária ao senso comum, frequentemente difundido pelos grandes jornais, que representa o Brasil como intrinsecamente corrompido, a autora percebe na corrupção um dos sintomas de um país frágil no que diz respeito às suas instituições, mas passível de mudança conforme haja um aprofundamento dos valores democráticos.

No quinto capítulo, Schwarcz enfoca o tema da desigualdade social. A má distribuição da riqueza socialmente produzida, a disparidade de oportunidades, a discriminação racial, o desequilíbrio econômico entre as regióes Norte e Sul, a não equidade de gêneros e o acesso desigual à saúde, à educação, à moradia, ao transporte e ao lazer são algumas das expressóes da desigualdade social no Brasil. Um fenômeno que, segundo a autora, apesar de ser uma velha herança do nosso passado colonial e escravista, não deve ser encarado como um fardo necessário, mas como uma contingência, resultado da permanência de certas políticas que, por sua vez, podem ser alteradas em favor de medidas que assegurem a ampliação dos benefícios públicos para camadas cada vez mais amplas da população.

O problema da violência é abordado no sexto capítulo. O Brasil, de acordo com dados recentes apresentados pela pesquisa- 
dora, é um dos países com as maiores taxas de mortes violentas na América Latina. Não obstante, para além da violência urbana expressa nos altos índices de furtos, assaltos e assassinatos cometidos diariamente nas grandes cidades do País, Schwarcz nos chama a atenção também para a situação do campo. Segundo a autora, os conflitos pela posse de terras é hoje uma das maiores causas de mortes violentas no Brasil. Dentre as suas vítimas constam não só camponeses pobres engajados na luta pela reforma agrária, mas, sobretudo, indígenas e quilombolas violentados nos seus direitos constitucionais de possuírem, viverem e trabalharem nas terras que pertenceram a seus ancestrais. A negação do direito à terra a essas populaçóes, diz a autora, constitui um dos traços mais marcantes da nossa traição autoritária. Legado cultural que vê as minorias nacionais como "estrangeiras" e tende a negar-lhes ou anular direitos, mesmo que formalmente reconhecidos.

No sétimo capítulo, Schwarcz discute as questões de raça e gênero. Aqui, a historiadora argumenta no sentido de demonstrar como uma sociedade historicamente aferrada a marcadores sociais de natureza racial, sexual ou de gênero, por conta dos seus esforços em garantir a estabilidade das suas hierarquias e relações de subordinação, lida mal com as diversidades. As frequentes manifestaçóes de racismo, os múltiplos casos de feminicídio, a misoginia, a homofobia e a disseminação da cultura do estupro são traços de um autoritarismo que, cada vez mais, vem ganhando foros de política de Estado e que atualiza, nos dias de hoje, algumas das práticas mais abjetas e arcaicas da nossa experiência coletiva como nação.

Por fim, no oitavo e último capítulo, Schwarcz desenvolve o tema da intolerância. Palavra que, aqui, designa todo comportamento repressor que coage, por meio da intimidação moral ou da força física, indivíduos ou grupos portadores de opinióes, atitudes, crenças, modos de ser, que sejam percebidos pelos detentores do poder como reprováveis ou falsos. Nessa parte do livro, a autora contrasta a autoimagem que o brasileiro acostumou-se a fazer de si mesmo como avesso a conflitos, pacífico, democrático, no que se refere à convivência de gêneros, ideologias, raças e etnias, com o nosso extenso histórico de opressões, perseguiçôes e violências praticadas contra todos aqueles que, em diferentes momentos, foram compreendidos como sendo a alteridade da pátria oficial (os "outros" absolutos: o índio, escravo, pobre, comunista, estrangeiro, homossexual etc.).

Apesar de esforçar-se por estabelecer relaçóes dinâmicas entre passado e presente, em Sobre o autoritarismo brasileiro, Schwarcz não explica de forma mecânica um pelo outro. Não há a pretensão de estabelecer uma linha de continuidade direta entre a experiência colonial e escravocrata e todas as mazelas que sofremos nos dias atuais. Sua abordagem é mais sofisticada que isso e esforça-se por sublinhar as mediaçóes que existem entre os diferentes momentos da nossa história e a emergência de aspectos do nosso autoritarismo. Assim, conforme a visão da autora, os elementos que constituem a nossa herança autoritária são acionados e atualizados de tempos em tempos conforme 
a necessidade de manutenção de uma sociedade fortemente desigual e hierarquizada. É, pois, assim, que a autora nos faz perceber, por exemplo, os matizes das diferentes atualizaçóes do mito da democracia racial brasileira, com gênese ainda no século XIX, pleno desenvolvimento na década de 1930 e florescimentos ocasionais ainda nos dias de hoje. $\mathrm{O}$ mesmo para as manifestações coronelísticas na política atual, as práticas e os discursos genocidas realizados contra populaçôes negras e indígenas, a constante confusão entre o público e o privado na administração do Estado, o ódio e desprezo das nossas elites aos pobres, toda a sorte de violências e discriminaçóes sofridas por mulheres e LGBTTQs (Lésbicas, Gays, Bissexuais, Travestis, Transexuais e Queers), a intolerância contra a diversidade de pensamento e concepçóes de mundo (sejam elas políticas, morais ou religiosas). Enfim, todo o quadro que nos constitui hoje como uma sociedade em crise e convulsão.

A obra de Schwarcz é uma contribuição valiosa para o debate público atual. Numa época em que as Ciências Humanas vêm sendo sistematicamente desqualificadas e atacadas por governos e setores da sociedade civil, a pertinência de reflexões históricas críticas, bem embasadas e acessíveis ao público amplo é particularmente grande. Tanto no Brasil quanto no resto do mundo.

E, nesse sentido, Schwarcz é consciente e consequente. Além de acadêmica prolífica, a pesquisadora também vem atuando junto a plataformas digitais. Desde setembro de 2018, a autora mantém um canal no Youtube dedicado à explicação de conceitos históricos e sociológicos, bem como à problematização de temas referentes à política e sociedade brasileira, sempre à luz da reflexão científica recente. Uma atividade que, aliás, insere-se na tendência atual de intelectuais universitários ocuparem também certos espaços na internet compreendendo-os, sobretudo, como instrumentos de atuação política e formação de consciência crítica (caso, por exemplo, do semiólogo Wilson Ferreira, do psicanalista Christian Dunker, do sociólogo Jesé Souza, entre outros).

Numa época em que cada vez mais as novas tecnologias de comunicação têm sido utilizadas para disseminar desinformação, obscurantismo, intolerância e preconceitos, vem se formando, entre certos segmentos da intelectualidade progressista brasileira, o senso de que é necessário chegar ao grande público. Fazer-se ler e ouvir, de modo claro e acessível, por todos, muito além das conferências, congressos e seminários de pós-graduação. O livro Sobre o autoritarismo brasileiro cumpre bem esse papel. É uma obra densa, mas de linguagem simples, direta e que nos ajuda a compreender algo do que houve e do que ainda há no Brasil. Um país permanentemente assombrado, espantado consigo mesmo; mas também continuamente assombrado, obsidiado pelos seus muitos fantasmas.

\section{Referências}

CASTELLS, Manuel. Ruptura: a crise da democracia liberal. Rio de Janeiro: Zahar, 2018. 
LEVITSKY, Steven; ZIBLATT, Daniel Ziblatt. Como as democracias morrem. Rio de Janeiro: Zahar, 2018.

MAGALHÃES, Mário. Sobre lutas e lágrimas: uma biografia de 2018, o ano em que o Brasil flertou com o apocalipse. Rio de Janeiro: Record, 2019.

MOUNK, Yascha. O povo contra a democracia: por que nossa liberdade corre perigo e como salvá-la. Sáo Paulo: Companhia das Letras; 2019.

PINHEIRO-MACHADO, Rosana; FREIXO, Adriano de. Brasil em transe: bolsonarismo, nova direita e desdemocratização. Rio de Janeiro: Oficina Raquel, 2019.

SCHWARCZ, Lilia Katri Moritz. Sobre o autoritarismo brasileiro. São Paulo: Companhia das Letras, 2019.

SCHWARCZ, Lilia Katri Moritz. Lima Barreto: triste visionário. São Paulo: Com- panhia das Letras, 2017.

SCHWARCZ, Lilia Katri Moritz; STARLING, Heloisa Murgel. Brasil: uma biografia. Sáo Paulo: Companhia das Letras, 2015. SCHWARCZ, Lilia Katri Moritz. As barbas do Imperador: D. Pedro II, um monarca nos Trópicos. São Paulo: Companhia das Letras, 1998.

SCHWARCZ, Lilia Katri Moritz. O espetáculo das raças: cientistas, instituiçóes e pensamento racial no Brasil: 1870-1930. São Paulo: Companhia das Letras, 1993.

SOLANO, Esther. O ódio como politica: a reinvenção das direitas no Brasil. São Paulo: Boitempo, 2018.

SOUZA, Jessé. A elite do atraso: da escravidão à Lava Jato. São Paulo: Leya, 2017. TIBURI, Marcia. Delírio do poder: psicopoder e loucura coletiva na era da desinformaçáo. Rio de Janeiro: Record, 2019. 